Delft University of Technology

\title{
What Do You See in Your Bot? Lessons from KAS Bank
}

Oshri, llan; Plugge, Albert

DOI

10.1007/978-3-030-66834-1_9

Publication date

2021

Document Version

Accepted author manuscript

Published in

Digital Technologies for Global Sourcing of Services - 14th International Workshop on Global Sourcing of Information Technology and Business Processes, Global Sourcing 2019, Proceedings

\section{Citation (APA)}

Oshri, I., \& Plugge, A. (2021). What Do You See in Your Bot? Lessons from KAS Bank. In I. Oshri, J.

Kotlarsky, \& L. P. Willcocks (Eds.), Digital Technologies for Global Sourcing of Services - 14th International Workshop on Global Sourcing of Information Technology and Business Processes, Global Sourcing 2019, Proceedings (pp. 145-161). (Lecture Notes in Business Information Processing; Vol. 410). Springer Science+Business Media. https://doi.org/10.1007/978-3-030-66834-1_9

Important note

To cite this publication, please use the final published version (if applicable).

Please check the document version above.

\footnotetext{
Copyright

Other than for strictly personal use, it is not permitted to download, forward or distribute the text or part of it, without the consent of the author(s) and/or copyright holder(s), unless the work is under an open content license such as Creative Commons.

Takedown policy

Please contact us and provide details if you believe this document breaches copyrights.

We will remove access to the work immediately and investigate your claim.
} 


\title{
What Do You See In Your Bot? Lessons from KAS Bank
}

\author{
Ilan Oshri and Albert Plugge ${ }^{2}$ \\ Faculty of Business and Economics, \\ The University of Auckland, New Zealand \\ Faculty of Technology, Policy and Management, \\ Delft University of Technology, The Netherlands
}

\begin{abstract}
.
The introduction of robotic process automation (RPA) has created an opportunity for humans to interact with bots. While the promise of RPA has been widely discussed, there are reports suggesting that firms struggle to benefit from RPA. Clearly, interactions between bots and humans do not always yield expected efficiencies and service improvements. However, it is not completely clear what such human-bot interactions entail and how these interactions are perceived by humans. Based on a case study at the Dutch KAS Bank, this paper presents three challenges faced by humans, and consequently the perspectives humans develop about bots and their abilities to perform work. We then provide a set of five practices that are associated with the management of the interactions between humans and bots.
\end{abstract}

Keywords: Human-Bot interaction, RPA, Case Study, Challenges and Practices

\section{Introduction}

The last decade has witnessed a tremendous interest in the automation of services through what has been coined as robotic process automation (RPA). RPA refers to the application of software programs that process certain tasks previously performed by humans $[1 ; 2 ; 3]$. RPA has been implemented to automate repetitive and rule-based functions typically handled by back-office employees. In selecting a can didate function for a utomation, firms usually consider certain criteria such as the degree of process complexity, the degree of human interventions and human-bot hand-overs, and the degree of structured data usage [4]. Typical processes that have been automated are cost accounting, payables and receivables, reporting, invoice sharing, and month-end close processes. A recent study by KPMG [5] on intelligent automation (IA), an umbrella term for RPA, machine learning a nd artificial intelligence, predicts that global spending on such technologies will reach \$US232 billion by 2025. Recent reports have persistently suggested that RPA is likely to deliver significant benefits to firms. For 
exa mple, it has been suggested that RPA is likely to increase the a ccuracy of business operations by minimizing human error, execute business processes with extreme precision at very high velocity, improved capabilities including monitoring and analytics, allow to scale-up processing infra structure while significantly reducing operational cost [6; 7]. Literature on RPA identifies various practical implementations both from a client and service provider perspective. From a client side, Lacity and Willcocks [4] studied RPA implementations at $\mathrm{O} 2$ which focused on transforming back office services. From a service provider side, the example of OpusCapita, which provides Business Process Outsourcing (BPO) services, started its journey by focusing on the internal adoption of RPA, and next moved to implementing RPA solutions for its clients [8].

While the promise of RPA has been widely discussed in the popular and professional media $[9 ; 10]$, there have been numerous reports suggesting that firms struggle to benefit from this technology $[11 ; 12]$. A KPMG report [5] has suggested that while firms have high expectations to benefit from such technologies, in reality many fims have developed a relatively low level of rea diness to deploy such solutions. Deloitte's [13] study has further stated that intelligent automation will ha ve severe impact on new ways of working, challenging the firm's a bility to cope with change needed within the firm, such as, a ugmenting human work with smart machines. As bots and humans are expected to work together, failing to a ugment them will have negative consequences for both human and bot performance. Indeed, unlike the implementation of robots in manufacturing where robots' actions are visible thus a llowing humans to anticipate colla boration and hence a djust their behaviors according to observed robot's a ctivities, in the case of RPA, software bots operate with very little visibility for the individuals who interact with them, thus making their ability to anticipate action and adjust behavior more challenging. In this regard, the challenges that humans reported about working side-by-side software bots at the workplace is key to understanding human's ability to collaborate and engage with them [14]. The aim of our research is to show how humans and bots interact within the context of a firm's implementation of RPA, based on the following research questions: (i) what challenges employees face when interacting with bots and (ii) how firms can mitigate these risks.

We studied a bot implementation program at KAS Bank, a financial institution based in the Netherlands, with an emphasis on the challenges that humans reported when software bots were introduced in their work en vironment. We first present our research methodology. Next, we introduce KAS Bank's bots program followed by our analysis of the interactions between humans and bots. Subsequently, we high light the challenges humans faced in such interactions and conclude with a set of practices assisting individuals to develop a perspective on bots. 


\section{Research Methodology}

Since empirical research related to human-bot interaction is limited the aim of our research is to show how humans and bots interact within the context of a firm's implementation of RPA. As such, we opted for an exploratory, case-study-based research that will ga in us a deep understanding of the phenomenon under study [15]. A case study approach does not allow statistical generalization since the number of entities as described in case studies is too small. However, our main objective is to expand and generalize theories (analytical generalization) and not to enumerate frequencies (statistical generalization) [15]. Applying a semi-structured interview method as a research instrument is useful to select data and information for exploratorydescriptive studies that may be extended later [16]. We use two main criteria to select a case study in which humans and bots interact. First, we identify a business process that is transactional by nature and routine-based. Second, we select a type of business process that can be characterized by frequent interactions between humans and bots as these type of processes a re perceived to be complex due to interdependencies between actors. We selected a case study in which a client automated various financial-oriented business processes. An independent Dutch Bank was selected that is considered a lea ding European provider of custodian and fund administration services, offering tailored financial services to institutional investors and financial institutions.

We collected data by conducting in-depth interviews during two visits to KAS Bank based in Amsterdam, The Netherlands. In the first visit, we collected and studied corporate information (website, press releases, RPA presentation, RPA blueprints and process information). In the second visit we collected qualitative interview data from 15 KAS Bank representatives that comprise various roles (see Appendix for the interviewee list). All interviews were recorded and transcribed and discussed by the two researchers. We conducted interviews with client representatives, including business and IT management, audit manager, software programmer, process designers, and business process experts. In this way we a void 'elite bias'. The interviews were semi-structured and based on a protocol that included open questions on how to identify human-bot interaction challenges. In total we conducted 15 interviews and all interviewed participants had been engaged in human-bot interactions (see Appendix). This was to ensure internal consistency within the business process landscape. The varying hierarchical levels of the interviewed staff members prevent potential limitations of the evolving phenomenon from arising. The interviewees were asked to describe their role in human-bot interactions and specifically how they dealt with challenges. Interviews varied from 30 minutes to 120 minutes in duration. Additional information was gathered from company information, business process information, and RPA configurations and reports. All the interviews were then tra nscribed, and the transcripts were sent to the participants to be confirmed.

When executing our qualitative research concept maps are used to guide us through the process of da ta a naly sis. Since knowledge is fairly nonlinear, concepts can be seen as organized networks. By selecting and organizing relevant information we are able to identify links between concepts, so that we can fathom the data [17]. Interview data of 
the staff members was translated into concept maps. As a result of the coding process we were able to crea te more insight in relev ant concepts and human-bot interactions.

\section{KAS BANK Bot Program}

KAS Bank is an independent Dutch bank founded in 1806. The bank is considered to be a lea ding European provider of custodian and fund administration services providing tailor-made financial services to institutional investors and financial institutions. As a response to market developments, KAS Bank decided in 2014 to initiate a cost reduction program to minimize operating costs. A LEAN program was launched to strea mline and simplify financial business processes at the bank. However, the results were not sufficient enough to meet the cost reduction program's objective. As a result, KAS Bank outsourced a number of IT functions to a service provider, a deal that included the transfer of employees a nd IT a ssets. The outsourcing program has proven to be successful, delivering both significant costs reductions and flexibility regarding pricing mechanisms (pay per use). The bank's executives were encouraged by these results and sought to explore a dditional mechanisms through which cost reductions can be achieved. In 2016, KAS Bank's operations department has introduced the RPA progra $\mathrm{m}$. The RPA journey started with KAS Bank exploring the a utomation of some standard processes. Candidate processes were analyzed in two steps. First, four main criteria were used to assess which processes were ideal to be included in the RPA progra $\mathrm{m}$. These revolve around (i) how much transactional oriented the process was, (ii) whether the process was routine-based, (iii) whether these were repetitive tasks, and (iv) whether the process was of low complexity (standardized). As second step, three a spects are used to rank the score corresponding with the (i) degree of feasibility, (ii) impact on service quality and (iii) impact on customer management (see Figure 1).

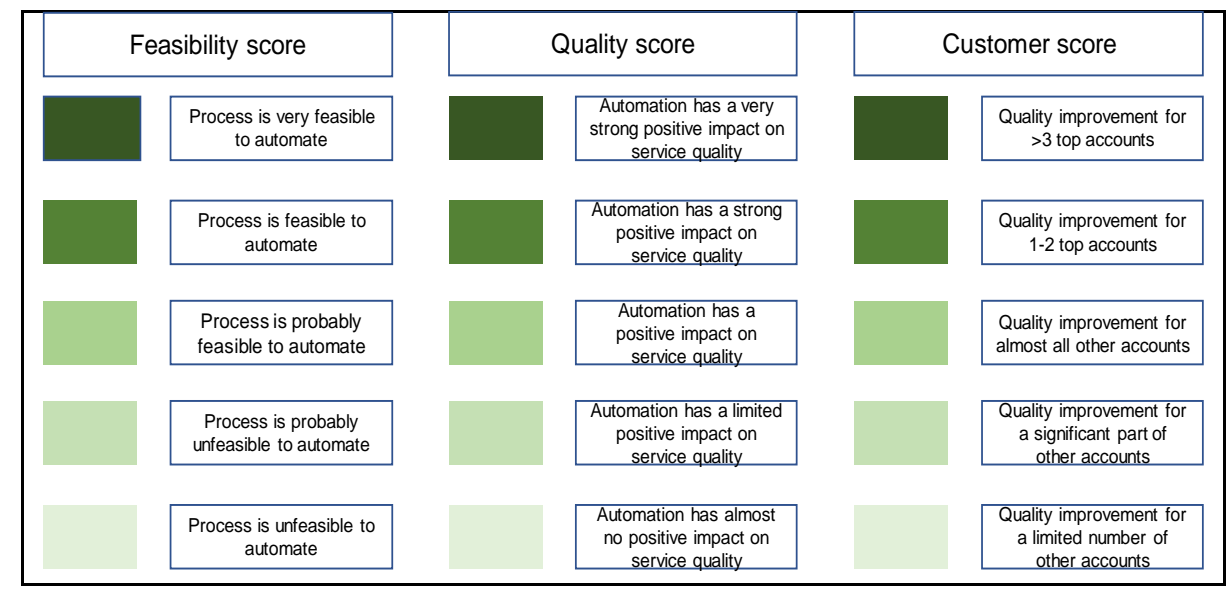

Fig. 1. Overview selection criteria (step2) 
Using this selection method, the operations department a ssessed numerous business processes. Consequently, a businesscase was developed per each businessprocess that was identified as promising for a utomation in which various aspects were analyzed, such a s, the impact of a utomation on the degree of business process im provement, cost involved, the needed support in terms of information systems and people, and the time to market, for instance, for tra ding services. By indicating the impact on each business process through automation, KAS Bank was able to define the value delivered to their clients and the value provided to KAS Bank in itself. At the start in 2016, two business processes were automated within 6 weeks. This included the development of a planning scheme, build of the bot, and a two-week implementation. More recent bots were introduced over eight weeks that consist of a six weeks development period and two weeks implementation period. In many ways, KAS Bank's bot implementation approach is consistent with [8] in which a four-stage approach (workshop, process a ssessment, business case proposal, RPA implementation) wa s pursued. At the time of data collection, KAS Bank automated 20 financial business processes using five bots. Among the various business processes automated at KAS Bank are treasury operations, obligation payments, calculating and booking, and client data management (e.g. internal invoicing, opening new and changing existing bank accounts). Bots implemented at KAS BANK have taken over manual processed transactions which were carried out by employees using Excel spread sheets. Many of these employees carried out this line of work for over a decade. While the original in troduction of bots was to reduce cost, recent automation projects sought to im prove the quality of business processes by removing and skipping rework.

\section{Humans and Bots: The Challenges}

Although the benefits of using RPA have been addressed in academic literature and practice [18], challenges associated with the visibility of bots' actions and hence humans' reaction havenotbeen addressed so far. Our examination of KAS Bank's bot program suggests that 3 key visibility challenges evolved that led humans to struggle with in their software bots environment. We discuss these three areas of visibility below.

\subsection{Challenge 1: The Visibility to the Bot Concept}

Ba sed on our interviews at KAS Bank we noticed that employees were struggling with the concept of bots. More particularly, the following questions were raised by employees: what bots are? how do they work? what can they deliver to the firm? and how are they able to fulfil employees tasks? Thesequestions correspond with [19] work who studied the RPA concept and its implications for financial processes. We frame this challenge as the visibility of employees to the bot concept. At KAS Bank, employees were first skeptical about what bots were and their ability to perform tasks previously carried out by humans. Indeed, employees' perception of what bots can or 
cannot do varied significantly. When the Bot Program was discussed as an option, most operations employees were skeptical about the concept. In fact, some of them cha llenged the bot's ability to replace them and perform a task they have carried out for a while. They have perceived their unique and of ten undocumented knowledge and experience to be critical for the completion of the task, despite their work being categorized as rule-based and repetitive.

"During the start of the program employees were skeptical as they did not believe that their skills and experience could be copied by a software program. The idea that bots do exact the same things as humans do was not accepted: they did not believe that it could work." (Source: softwareprogrammer).

During KAS Bank's initiation of the bot program employees discussed the concept of applying bots as part of business processes and argued that they did not understand the concept. Actually, the majority of employees were not aware that software is used to fulfill business oriented tasks. By explaining how a bot looks like and what bots can and cannot do, employees were informed a bout the practical consequences.

"Various employees didnot understand how the robot works and what type of tasks are conducted. We learned that we have to explain how bots work and how they fit into a businessprocess." (Source: process designer).

As part of KAS Bank's explanation how bots work employeeswere informed about the fact that a bot is just a software program and that the IT department will program business rules in the software bot. As a consequence, process managers have to sketch out business process tasks first. Subsequently, an IT department software programmer is able to configure the bot and translate process descriptions into program rules. In doing so, employees created a better understanding of how humans and bots work together.

\subsection{Challenge 2: Visibility to the end-to-end business process}

The introduction of bots to the operations environment also created a process challenge. Operations personnel who were manually performing tasks to be automated have developed over the years a partial understanding of the business process. These personnel have become accustomed to focus on da ta entry and problem solving of specific process steps, that the big picture of what the transaction represents have become hidden to them. KAS Bank established a development team to implement the bots, however, the team struggled to compose the end-to-end business process as operations personnel could only provide information on segregated steps that involved multiple teams and across departments. As a result, the development team had difficulties in configuring the bots for an end-to-end bu siness process. Bots, therefore, were eventually configured to handle an amalgam of transactions. The following sta tements reflect on this a spect: 
"We experienced that employees who are fulfilling process steps just focus on their dedicated tasksand haveless insights in otherprocess related tasks. In fact, employees have builta specific profile in conducting tasks. Since we introduced bots, we noticed that employees have to understand the process as a whole, which require a more generic profile." (Source: Business Process Manager Finance 1)

"Previously, employees performed repetitive tasks. Today [after automation], they have to understand process tasks and interpret which tasks they still have to do themselves. This means that employees need to understand the process as a whole to collaborate with a robot successfully." (Source: Business Process Selection Specialist)

As during the introduction of RPA at KAS Bank certain process steps were replaced by bots, employees became confused about 'who is doing what' as they did not have an overall view of the process. Originally, employees knew who to contact in case of unclarities for instance in case of process hand-overs. Now, bots have taken over the majority of process tasks, which increased the unclarity of mutualresponsibilities. As a result, employees showed resistant behavior to fulfill their ta sks. This corresponds with [20] study who pointed out that RPA solutions require firms to consider the endto-end process. While firms benefit from integra ting sub-processes and tasks into an end-to-end automated process, humans' involvement and understanding of the process can be hindered by the automated process, as demonstrated in the KAS Bank case.

\subsection{Challenge 3: Visibility to solve what bots cannot process}

As bots became operational, they processed transactions that previously were manually performed by humans. Bots depend on in putdata to generate meaningful output. Their output, often in the form of a report, was handed over to operations employees who needed to check it prior to passing it on to an external client. The development team a ssumed that data provided as input from internal a nd ex ternal sources would bein line with the bots' requirements, thus resulting in the generation of a client report. Operations personnel were consequently informed about their new responsibilities to check the reports before releasing them to clients. At the same, the development team informed operations personnel that their work was affected by bots to ident ify the impact of bots' implementation and consequently adapt their way of working. Yet, the full impact of robotizing ta sks was not a ssessed as data provided as input was not always complete or a ccurate.

Bots at KAS Bank were not always able to process tasks they were designed to complete. When a bot failed to complete a task, the incomplete task was flagged as an exception. In most cases, when bots generated exceptions, it was because data was either incomplete or incorrect. For example, a data field which was defined as numeric contained letters and therefore produced an exception by the bot. As an output, the bot produced an exception report to be reviewed and corrected by operations personnel (see figure 2 - example of an exception report). As a result, operations personnel have become essential for the completion of tasks that the bot has failed to complete. 
"Within a business process at least $40 \%$ of all tasks can be conducted by a bot, but often more. The percentage is influenced by the number of exceptions regarding process tasks. Specifically, the data quality is a real issue as bots are rejecting tasks in case of poor data quality. That's where the humans come in as they have to repair the quality of datafirst.' (Source: Functional Application Manager).

"A design criterion is a bothas to handle 2000 financial (swift) transactions per week. Based on our conducted proof of concept we experienced that $20 \%$ of all transactions were labelled as exceptions. That means that we still need humans to repair bot errors." (Source: Software Programmer)

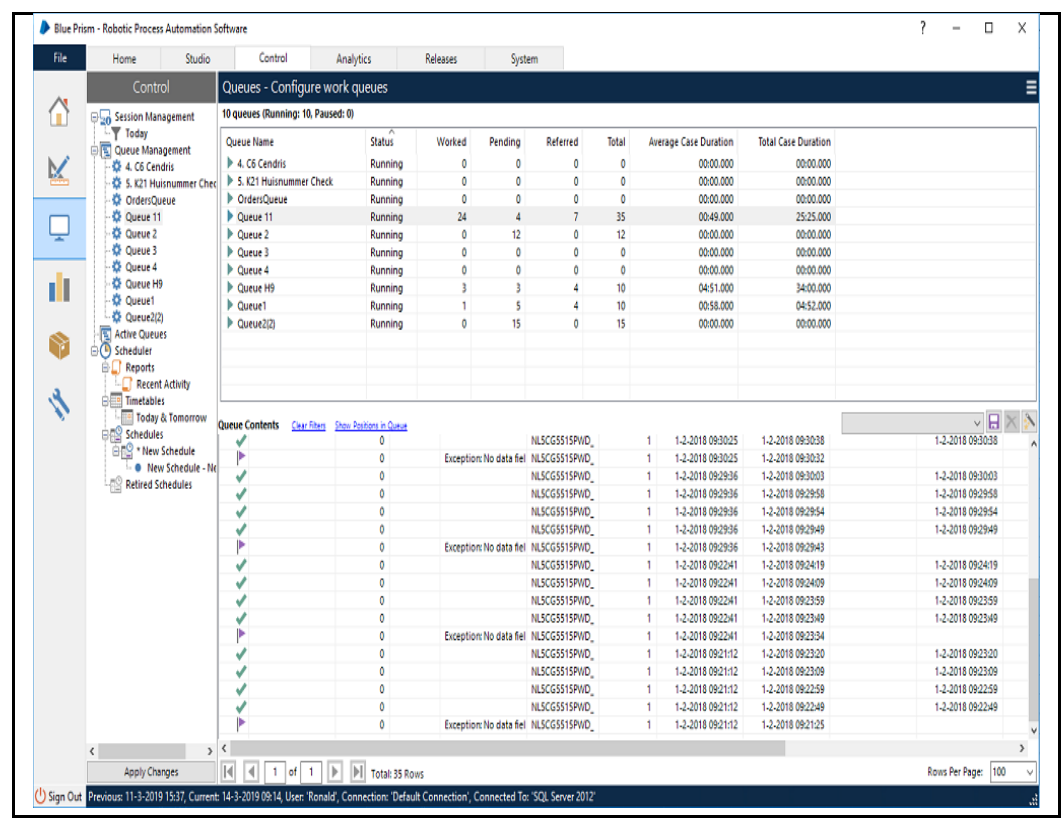

Fig. 2. Exa mple of an RPA exception list

The observation that not all process steps can be automated correspond to the research of [21] who state that the aim of a utomation is to replace human manual control by automatic devices and computers. The author's findings suggest that the increased interest in hum an factors reflects the irony that the more a dvanced a control system is, the more crucial the contribution of the human operator.

As a result of bot exceptions at KAS Bank, operations personnel needed to engage in work they previously manually performed, however in a different way. Previously they entered data for all the fields, but now they needed to analyze the source of the exception and consequently complete the missing/wrong information. Handling exceptions have changed the operations personnel's' roles in two ways. On the one 
hand, some operations personnel pursued a root-cause analysis and engaged in redesigning the process by working with the development team to a void the reoccurrence of these exceptions. These initiatives required KAS Bank to provide operations personnel opportunities to develop themselves further and assume a process improvement manager role. On the other hand, other operations personnel were finding the task of handling exceptions as discouraging. While in the past these individuals were responsible for assessing the quality of the data as input, allocate the data field that the data should be entered and complete data entry, now these individuals are instructed by the bot to decode the nature of the exception and take steps to fix this specific mistake. They have little visibility to the inputdata, and yet, they require to fix it. Consequently, these operations personnel sought alternative lines of employment.

The three challenges demonstrate that because humans lacked visibility to what bots a re, do and fail to do, firms need to address these shortcomings by a ssisting humans to collaborate with bots. Based on our observations at KAS Bank, we developed practices to overcome such challenges and improve human visibility to what bots a re and do.

\section{Five Practices to Help Introducing Humans to Bots}

We offer five practices the improve visibility of what bots are and do, as well a s how humans should engage with bots' outcomes based on observations made atKAS Bank. Two practices rela te to the visibility to the bot concept, one to visibility to the end-toend business process , and one to visibility to solve what bots cannot process.

\subsection{Practice \#1. Humanize the Bot}

Any bot program will encounter behavioral change by employees toward the bot during the implementation stage. At KAS Bank, employees were first skeptical about the impact of bots on their jobs, and the ability of bots to replace them. Gradually, employees became a ware of what bots can and cannot do. Interestingly, we noticed that post-implementation, employees referred to bots operating in their environment as if they were another human colleague. They attributed success and failure to the bot, despite the fact that a bot's performance is a direct outcome of the quality of a software progra $m$. Further, the development team gave each bot a comic hero name, and in sisted on referring to the bot by its na me in any communications.

"We also use bot names in our internal communications about performance and exceptions. As we inform teams and employees about the progress and benefits of automation, the bot names become familiar." (Source: Head Process Improvement)

Our observations suggest that as soon as the bots are implemented, employees try to find the human being in the bots. Phrases such as "we have a new co-worker: <name comic hero >" and " $<$ name comic hero $>$ does act strange, we need to help him" were often used. We even noticed that employees praised the bots for fulfilling a lot of work. 
One business process manager stated that "we need to get the bot out of the humans and get the human into the bot". Indeed, each new bot was registered as a new team member, which included assigning training sessions and clearly defining their tasks, just as for any human worker. Such a practice helps humans to visibility of what the bots are and treat them as co-workers, allowing them to understand the bots' areas of responsibilities a nd a bilities. Our findings a re consistent with the research of [22] who studied theintegration of robots into a hospital workflow. Indeed, with increased stress levels by ca regivers, so the emotional response to the robot increases by humans around the robot.

\subsection{Practice \#2. Visualize the Bot}

Our case at KAS Bank shows that it was important to visualize what bots do. We observed that the design teamat the Bank pursued several steps to improve visibility of what bots do and are during the design and implementation stages. First, presentations were organized for all departments and teams a s an internal roa dshow. Then, the Bank held sessions in which simulations of the bots' functionalities were shared with employees, and what the manually performed tasks would look like in an automated workflow. Lastly, when a bot was implemented, the Bank repeated the workflow presentations to show how the bot operated in the live environment. A workflow chart (see figure 3) was placed in operations team offices to en sure that they could clearly see how 'their' bots performed work and a ssess the junctions where humans could be needed to complete the task.

"The process graphics helped to understand what tasks are fulfilled by bots and these insights are helpful for handling exceptions, which in turn is a new task of process experts. Moreover, both the Proof of Concept and the graphics helped to build trust in the bots as we haveto rely on them." (Source: Business Process Manager Finance 2) 


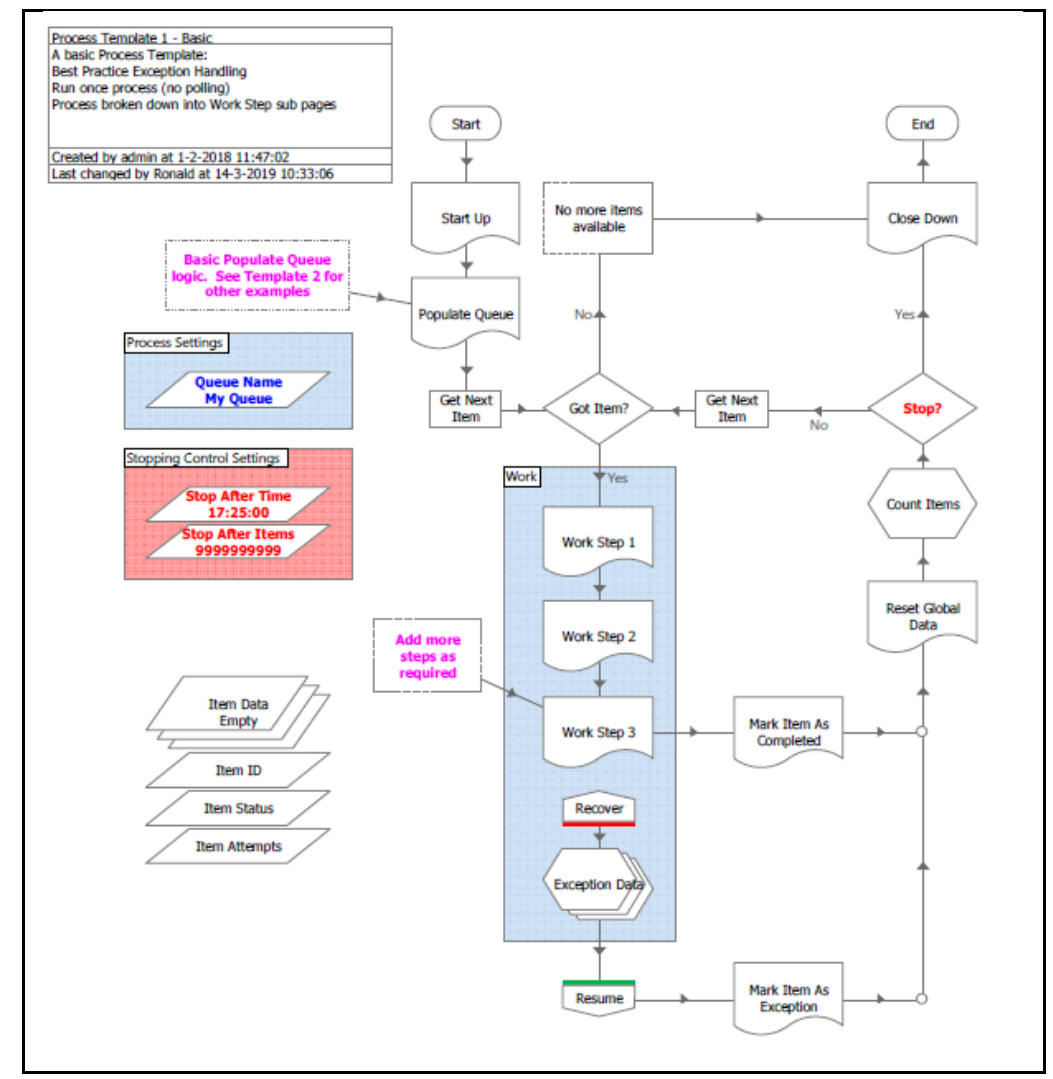

Fig.3. Example Business Process visualization

Showing bots in a live environment stimulated interest and generated discussions within the Bank with rega rd to thebots' impacton work. Questions such as "How long will it ta ke to programa bot?", "What is the IT view on managing bots?" "Can the bot do other tasks?", and "How does the bot make decisions?" were ra ised in these meetings, further helping people to understand and further clarity some of bots' abilities and theirimpact on human work. These findings correspond with [23] work in which they argue that employees involved in a ccounting processes need to understand how to unpack human-machine interactions. We provide insight into the steps and actions that improve such visibility by humans of bots to allow humans relate to what bots do and how they do that.

\subsection{Practice \#3. Help Humans visualize positive human-bot interactions}

One of the challenges we observed was that the lack of visibility to what bots do and consequently the need for humans to 'pick-up' exceptions and complete tasks the bot failed to complete created a sense of fru stration and resentment a mong em ployees. As 
such, the true threat of bots wa snot necessarily in that bots replace humans, but humans losing ownership of the tasks and processes, thus finding themselves as 'fixing' bots issues. We find that after employees became fa miliar with working with bots they experienced the a dvantages. One expert stressed the positive impact some employees experienced:

"After the implementation of the bots in our business processes some colleagues try to find the human in the robot. The say 'the bot does not work!, we as humans will fix the problem' or 'the robot does act strange, we need to give him a hand.' We also experienced that colleagues are praising the bots to full fil lot of work. Moreover, they state that they have a new co-worker: a bot." (Source: Process Designer 2).

At KAS Bank, there were hardly any redundancies following the implementation of the bots program, however, severaloperators, who were previou sly involved in da ta entry, sought alternative lines of employment as they struggled to cope with the changing nature of the job. Such an outcome can be mitigated should management offer new career a venues that will re-esta blish links between humans and bots. For example, we observed that some operations personnel were encouraged and took on developing process improvement skills during robotization. Some used their freed-up time to get training in advanced areas of management and invested in developing relationships with clients. Or a s an expert argued:

"Business process operators do not necessarily lose their jobs, with only a limited number compared to our original expectations. Instead, they have foc used on process improvements and providing services such as financial reporting to our external clients on a regular basis." (Source: Business Process Expert Finance 1).

Indeed, RPA implementation requires changes in business processes. In this regard, helping individuals become process leaders is therefore key to maintaining human involvement in the bots program. KAS Bank introduced new roles called 'process cha mpions' who were in volved in training and educating others about taking ownership of the entire bot business process. Consequently, em ployees learned when and how to interact with bots, and how exceptions should be handled. Moreover, process cha mpions propagated a LEAN methodology, which encouraged employees to identify process improvements on a daily basis and continue to improve bot operations. One process expert explained:

"Process experts create an in-depth understanding of how robots are built and what type of tasks they perform to identify improvement initiatives. By encouraging the use of bots and aligning human-bot interactions, our processchampions fulfill a vital role. Through providing examples, answering questions, and discussing process and bot improvements with their colleagues, they accelerate the performance of robotized processes." (Source: Business Process Expert Finance 2)

Process champions also conducted two-monthly reviews of bot workflows. The review reports offered a better understanding of how many tasks had been fulfilled by bots and provided root-cause a naly sis of tasks the bots had failed to complete. The report and 
the review process created opportunities for stakeholders to engage in improving the bots' workflow and performance. One manager highlighted the a dvantages of this function:

"Employees are encouraged to provide input to tweak/fine tune the robot. The goal is to provide improvement suggestions through which process taskscan be simplified and operate faster. Based on our findings, the robotics development team learned how to optimize process steps and decrease the number of process failures. It's a process itself to train the robot in handling tasks even better and better." (Source: Functional Application Manager)

As claimed by [24], process skills are essential when applying RPA solutions, not just to improve efficiencies but a lso to help humans relate a nd visualize opportunities to be part of the bots program.

\subsection{Practice \#4. Making bots governance more visible}

Humans respond to either formal or informal governance mechanisms but interpreting desired outcomes and anticipating rewards or penalties. However, humans may struggle understanding their interactions with bots should there not be a governing structure for such interactions. In this regard, humans lack visibility of how bots are govemed. In our case, KAS Bank established a unique Center of Excellence (CoE) to coherently govern human-bot interactions. The CoE's objectives were twofold. First, it was responsible for governing a wide range of tasks, such a s: establishing bot ownership, verifying general audit and IT controls (e.g. authorization), separation of duties, roles and responsibilities, and legal issues. From a control and reporting perspective, the $\mathrm{CoE}$ was responsible for KAS Bank fulfilling its obligation to show compliance with financial and IT regulation standards (e.g. ISAE 3402) and report their findings to clients. In addition, the $\mathrm{CoE}$ coordinated end-to-end business process, in particular when various sub-processes were managed by a number of departments. This was done in collaboration with the IT department who were responsible for the operational management of the bots. One manager explained:

"We are managing one business process end-to-end, which consists of three subprocesses that are allmanaged individually byvarious business teams. Per sub-process exceptions are handled, however, one employee coordinates the end-to end process." (Source: Business Process Manager Finance 2)

In addition to humans governing bots, the governance structure also included the management of data quality, such a scompleteness, accuracy, integrity and consistency. This a spect in governance is a lso important for the human-bot interactions as exceptions are genera ted by the bots are the result of low quality data but have to be resolved by humans. Data management governance allowed humans in the bots program to engage in data quality issues and redesign data structures that improve the bot's performance. One manager explained: 
"As data quality becomes important, in our view business data owners have to guard and improve data quality. KAS Bank's strategy is to become a more data driven company. That means that we definitely have to improve the quality of data if we intend to extend the number of bots in the near future." (Source: Business Process Manager Finance 1)

For humans to be in volved in governing bots, multiple a spects of governance should be considered such as roles, process ownership, data management and expected performance.

\subsection{Practice \#5. Visualize the Bot}

The firm's service roadmap should capture the opportunities for collaboration between humans and bots. By developing a tightly coupled bot-human roadmap, firms will ensure that humans and smart automation platforms interact. As a consequence, a bothum an roadmap has to be translated into an operational plan to support business needs by means of an enabling IT landscape. Moreover, a sound architectural view can be seen as a prerequisite to support such an IT landscape. The Bank's enterprise architect explained:

"A bot-human roadmap consists of IT architectural blueprints, and clear IT boundaries (infrastructure, applications, data) that can be translated into a strategic bot agenda which can be managed by our senior managers. Therefore, we need a roadmap to align KAS Bank's business goals with an adequate IT landscape." (Source: Enterprise Architect).

Identifying the sweet spot between fully human and fully autonomous robotic processes will enable firm s to a nticipate the hand-over points between automation platforms and humans [25]. By developing a bot-human roadmap firms also pay attention to implement bots a s part of an IT landscape. In doing so, interoperability agreements towards existing information systems (applications, middleware, infrastructure) are established which improve the robustness of robotized business processes. We noticed that KAS Bank's architects focus on a pplying standards to decrease the number of bot exceptionsdue to failing IT malfunction. Business departments increasing dependency on bots that are capable of handling la rge volumes of work put additional pressure on the IT department to repair bots swiftly. By using design principles a rchitects aim is to design a coherent IT landscape to increase operational bot performance.

"In the near future KAS Bank intends to use cognitive solutions which are able to handle even more complex process exceptions. This will result in an additional pressure to our IT departments to sustain their operational performance." (Source: Managing Director Operations)

Next, we have listed the key challenges and rela ted RPA practices in table 1. 
Table 1. Challenges and related RPA practices

\begin{tabular}{|c|c|c|}
\hline $\begin{array}{c}\text { Key } \\
\text { challenges }\end{array}$ & & RPA practices \\
\hline \multirow{4}{*}{$\begin{array}{l}\text { Visibility to } \\
\text { the Bot } \\
\text { Concept }\end{array}$} & \multirow{2}{*}{$\begin{array}{l}\text { 1.Humanize your } \\
\text { bot }\end{array}$} & $\begin{array}{l}\text { Treat bots as human beings and co-workers to } \\
\text { a chieve a cceptance }\end{array}$ \\
\hline & & $\begin{array}{l}\text { Train bots to do exactly the same tasks as } \\
\text { humans do }\end{array}$ \\
\hline & \multirow{2}{*}{ 2. Visua lize the bot } & $\begin{array}{l}\text { Demonstrate how bots work in practice to } \\
\text { explore opportunities }\end{array}$ \\
\hline & & $\begin{array}{l}\text { Visua lize process steps to create a better } \\
\text { understanding }\end{array}$ \\
\hline \multirow{2}{*}{$\begin{array}{l}\text { Visibility to } \\
\text { the End-to- } \\
\text { End } \\
\text { business } \\
\text { process }\end{array}$} & \multirow{2}{*}{$\begin{array}{l}\text { 3.Help humans } \\
\text { visualize positive } \\
\text { human-bot } \\
\text { interactions }\end{array}$} & $\begin{array}{l}\text { Develop job rotation opportunities for } \\
\text { employees who seek alternative lines of } \\
\text { employment }\end{array}$ \\
\hline & & $\begin{array}{l}\text { Encourage process champions to educate } \\
\text { collegues about taking ownership of the entire } \\
\text { bot business process }\end{array}$ \\
\hline \multirow{4}{*}{$\begin{array}{l}\text { Visibility to } \\
\text { solve what } \\
\text { bots } \\
\text { cannot } \\
\text { process }\end{array}$} & \multirow{2}{*}{$\begin{array}{l}\text { 4. Making bots } \\
\text { governance visible }\end{array}$} & $\begin{array}{l}\text { Establish a Center of Excellence }(\mathrm{CoE}) \text { to } \\
\text { coherently govern human-bot challenges }\end{array}$ \\
\hline & & $\begin{array}{l}\text { Develop a data governance policy and plan to } \\
\text { a ssess a nd improve the quality of data }\end{array}$ \\
\hline & \multirow[b]{2}{*}{$\begin{array}{l}\text { 5. Visibility into } \\
\text { the bot-human } \\
\text { roadmap }\end{array}$} & $\begin{array}{l}\text { Ensure that humans and intelligent automation } \\
\text { platforms interact }\end{array}$ \\
\hline & & $\begin{array}{l}\text { Identify the sweet spot between fully human } \\
\text { and fully autonomous robotic processes to } \\
\text { a nticipate the hand-over areas and } \\
\text { consequently develop a strategic bot-human } \\
\text { roadmap }\end{array}$ \\
\hline
\end{tabular}

\section{Concluding Remarks}

This study is guided by the questions a) how does a firm address the employees' challenges that are a ssociated with RPA deployment, and b) what practices can be developed to overcome these challenges? The introduction of soft ware robotic solutions to support business processes leads to new organizational challenges. In this paper we examined interactions between humans and bots by describing three challenges that a client faced when implementing a bot program. Based on evidence we offered a set of practices that help firms to develop a perspective on what bots can and cannot do asa way to encourage humans' involvement in bot's work. As cognitive and artificial intelligence are likely replace additional areas of work, this article is a stepping stone in preparing humans to accept such solutions while a dvancing human skills. 


\section{References}

1. Leyh, C., Bley, K., and Seek, S.: Elicitation of processes in business process management in the era of digitization - the same techniques as decades ago? In: Piazolo, F., Geist, V., Brehm, L., Schmidt, R. (ed.) Innovations in Enterprise Information Systems Management and Engineering, 42-56. Springer International Publishing, Cham (2017)

2. Frank, M., Roehrig, P., and Pring, B.: What to do when machines do everything: How to get ahead in a world of AI, algorithms, bots, and big data'. John Wiley \& Sons (2017)

3. Wilson, H.J. and Daugherty, P.R.: Collaborative Intelligence: Humans and AI are Joining Forces. Harvard Business Review, July-August, 114-123 (2018)

4. Lacity, M. C. and Willcocks, L.P: Robotic Process Automation at Telefónica O2", MIS Q. Exec, 15,1, 21-35 (2016)

5. KPMG report 'Ready, Set, Fail? Avoiding setbacks in the intelligent automation race. https://advisory.kpmg.us/articles/2018/new-study-findings-read-ready-set-fail.html

6. Devarajan, Y.: A Study of Robotic Process Automation Use Cases Today for Tomorrow's Business, Int. J. of Comp. Tech., 5, 6, 12-18 (2018)

7. Leopold, H., van der Aa, H., and Reijers, H.A.: Identifying Candidate Tasks for Robotic Process Automation in Textual Process Descriptions. PMDS' 18 Working Conference, 11 12 June 2018, Tallinn, Estonia, http://www.bpmds.org (2018)

8. Hallikainen, P., Bekkhus, R., and Pan, S.: How OpusCapita Used Internal RPA Capabilities to Offer Services to Clients, MIS Q. Exec., 17, 1, 41-52. (2018)

9. Vernon, D.: Artificial Cognitive Systems. A Primer, MIT Press (2014)

10. Sundar, S.S., Bellur, S., Oh, J., Jia, H., and Kim, H.S.: Theoretical Importance of Contingency in Human Computer Interaction: Effects of Message Interactivity on User Engagement, Com. Res., 1-31 (2014)

11. McKinsey: Jobs lost, jobs gained: What the future of work will mean for jobs, skills, and wages. https://www.mckinsey.com/featured-insights/future-of-work/jobs-lost-jobs-gainedwhat-the-future-of-work-will-mean-for-jobs-skills-and-wages (2017)

12. Forrester Predictions 2019: Artificial Intelligence: No Pain, No Gain With Enterprise Al", Nov.6. https://www.forrester.com/report/Predictions+2019+Artificial+Intelligence/-/ERES144617 (2018)

13. Deloitte: The robots are ready. Are you? Untapped advantage in your digital workforce." https://www2.deloitte.com/content/dam/Deloitte/n1/Documents/strategy/deloitte-nlconsulting-robots-are-ready.pdf (2017)

14. Krämer, A.D., Guillory, J.E., and Hancock, J.T.: Experimental evidence of massive-scale emotional contagion through social networks. Proceedings of the National Academy of Sciences, 201320040 (2014)

15. Yin, R.K.: Case study research: design and methods. Sage Publications: London (2009)

16. Denzin, N.K.: The Research Act: A Theoretical Introduction to Sociological Methods. McGraw-Hill, New York (1978)

17. Orlikowski, W.J., Lacono, C.S.: Research commentary: desperately seeking the 'IT' in IT research- a call to theorizing the IT artifact. Inf. Syst. Res. 912, 2, 121-134 (2001)

18. Willcocks, L. P. and Lacity, M.C.: Service automation robots and the future of work. SB Publishing, Ashford, UK (2016)

19. Moffitt, K. C., Rozario, A.M., and Vasarhelyi, M.A.: Robotic Process Automation for Auditing. J. of Emer. Tech. in Acc., 15, 1, 1-10 (2018)

20. Kirchmer M., and Franz P.: Value-Driven Robotic Process Automation (RPA). In: Shishkov B. (eds) Business Modeling and Software Design. BMSD 2019. LNBIP, 356, Springer, Cham (2019)

21. Bainbridge, L.: Ironies of automation. Autom., 19, 6, 775-779(1983) 
22. Mutlu, B. and Forlizzi, J.: Robots in organizations: the role of workflow, social, and environmental factors in human-robot interaction, Proceedings of the 3rd ACM/IEEE international conference on Human robot interaction, 287-294 (2008)

23. Lehner, O., Leitner-Hanetseder, S., and Eisl, C.: The Whatness of Digital Accounting: Status Quo and Ways to Move Forward, ACRN J. of Fin. \& Risk Pers., 8, Special Issue Digital Accounting (2019)

24. Lamberton, C. Brigo, D., and Hoy, D.: Impact of Robotics, RPA and AI on the Insurance Industry: Challenges and Opportunities, J. of Fin. Pers., 4, 1, 8-20 (2017)

25. Kaivo-Oja, J., Roth, S., and Westerlund, L.: Futures of Robotics. Human Work in Digital Transformation. Int. J. of Tech. Mgt., 73, 4, 176-205 (2017)

\section{Appendix A}

Interview scheme and interview questions

\begin{tabular}{|l|l|}
\hline Role & Duration \\
\hline Manager Income and Tax & 30 minutes \\
\hline Audit Ma nager & 30 minutes \\
\hline Managing Director IT & 60 minutes \\
\hline Functional Application Manager & 50 minutes \\
\hline Managing Director Operations & 30 minutes \\
\hline Enterprise Architect & 45 minutes \\
\hline Software Programmer & 45 minutes \\
\hline HeadProcess Improvement & 30 minutes \\
\hline Process Designer 1 & 45 minutes \\
\hline Process Designer 2 & 45 minutes \\
\hline Business Process Selection Specialist & 120 minutes \\
\hline Business Process Manager Finance 1 & 45 minutes \\
\hline Business Process Manager Fina nce 2 & 45 minutes \\
\hline Business Process Ex pert Finance 1 & 45 minutes \\
\hline Business Process Expert Finance 2 & 30 minutes \\
\hline
\end{tabular}

\begin{tabular}{|c|l|}
\hline Category & Interview questions \\
\hline \multirow{3}{*}{$\begin{array}{c}\text { Generic } \\
\text { questions }\end{array}$} & $\begin{array}{l}\text { What was the firm's ra tionale to start robotizing financial business } \\
\text { processes? }\end{array}$ \\
\cline { 2 - 2 } & $\begin{array}{l}\text { How will the firm's fin a ncial bu sinessprocesses change due to } \\
\text { robotizing work? }\end{array}$ \\
\hline
\end{tabular}




\begin{tabular}{|c|c|}
\hline & $\begin{array}{l}\text { In general, do you have insights in what type of tasks are executed by } \\
\text { bots? }\end{array}$ \\
\hline & To what degree are you involved in robotized processes? \\
\hline \multirow{8}{*}{$\begin{array}{l}\text { Specific } \\
\text { questions }\end{array}$} & What process related tasks do you have to execute? \\
\hline & What are the efforts of robotization in practice? \\
\hline & What is the effect of robotization on employees (humans)? \\
\hline & $\begin{array}{l}\text { How is the handover determined a nd described between humans and } \\
\text { bots? }\end{array}$ \\
\hline & Who will pick up and execute the process exception list? \\
\hline & $\begin{array}{l}\text { To what degree does binding between humans and bots take place in } \\
\text { practice? }\end{array}$ \\
\hline & How is your expertise influenced by robotized businessprocesses? \\
\hline & $\begin{array}{l}\text { Who has oversight on the robotized processes in detail (steps, tasks, } \\
\text { responsibilities)? }\end{array}$ \\
\hline
\end{tabular}

